\title{
Overactive Bladder: Where We Are and Where We Are Going
}

\author{
Charan S. Mohan, ${ }^{\otimes 1}$ Wai Lee, ${ }^{1}$ Kathleen C. Kobashi ${ }^{2}$ \\ ${ }^{1}$ The Arthur Smith Institute for Urology, Northwell Health, New Hyde Park, United States \\ ${ }^{2}$ Section of Urology and Renal Transplantation, Virginia Mason Medical Center, Seattle, United States
}

\begin{abstract}
Overactive bladder $(\mathrm{OAB})$ is a heterogeneous syndrome estimated to affect approximately $10 \%$ to $15 \%$ of men and women globally. $\mathrm{OAB}$ not only negatively impacts quality of life but also results in a significant financial burden to both patients and health systems. Therefore, it is crucial that OAB is properly addressed. This manuscript provides a general review of the diagnostic algorithm for OAB and treatment per the AUA/SUFU guidelines, and an overview of new developments in $\mathrm{OAB}$ therapy. Given the wide array of therapeutic options that currently exist and those that are currently under development, there is tremendous opportunity to treat OAB successfully and positively affect our patients' lives.
\end{abstract}

\section{Introduction}

\section{Impact of Overactive Bladder}

Overactive bladder (OAB) affects approximately $10 \%$ to $15 \%$ of men and women, with some estimates placing prevalence as high as $27 \%$ for men and $43 \%$ for women[1-3]. Individuals with OAB have been shown to have poorer quality of life, higher rates of depression, and decreased rates of sexual fulfillment when compared with individuals who do not have OAB [4]. In a cohort of several North American and Western European nations, OAB-related expenses amounted to. $€ 1.2$ billion per year[5]. With the high prevalence of $\mathrm{OAB}$, the aging population, and the associated cost to the system, proper management of $\mathrm{OAB}$ is essential. This manuscript provides an overview of current treatment options and a discussion regarding new developments in advanced therapies.

\section{Defining Overactive Bladder}

OAB was first described as a clinical entity in the late 1980s[6]. The American Urological Association (AUA)/Society of Urodynamics, Female Pelvic Medicine and Urogenital Reconstruction (SUFU) OAB guidelines acknowledge the challenges in defining $\mathrm{OAB}$, as reflected by the number of statements that are based upon expert opinion rather than scientific publications. Joint work by the International Urogynecological Association (IUGA) and International Continence Society (ICS) defines OAB as "urinary urgency, usually accompanied by frequency and nocturia, with or without urgency urinary incontinence (UUI), in the absence of urinary tract infection (UTI) or other obvious pathology" [7]. Figure 1 shows an algorithm proposed by the authors to guide the evaluation of patients with OAB symptoms. While not a guideline, this pathway can offer clinicians, particularly those not familiar with OAB management, a structured approach to managing these patients.

\section{Key Words}

Overactive bladder, therapeutics, urgency urinary incontinence

\section{Competing Interests}

None declared

\section{Article Information}

Received on March 15, 2021

Accepted on July 4, 2021

Soc Int Urol J.2021;2(5):311-322

DOI: 10.48083/HZVQ6675 


\author{
Abbreviations \\ AUA American Urological Association \\ BPH benign prostatic hypertrophy \\ BTX onabotulinumtoxinA \\ CNS central nervous system \\ DO detrusor overactivity \\ GSM genitourinary syndrome of menopause \\ $\mathrm{MRI}$ magnetic resonance imaging \\ $\mathrm{OAB}$ overactive bladder \\ PRO patient-reported outcomes \\ RCT randomized control trial \\ SNM sacral neuromodulation \\ SUFU Society of Urodynamics, Female Pelvic Medicine, and \\ Urogenital Reconstruction \\ SUI stress urinary incontinence \\ UDS urodynamics \\ US ultrasound \\ UTI urinary tract infection \\ UUI urge urinary incontinence
}

\section{Methods}

A comprehensive literature search was performed using PubMed regarding (1) the pathophysiology of $\mathrm{OAB},(2)$ treatment options for $\mathrm{OAB}$, and (3) special considerations with respect to $\mathrm{OAB}$ management. Approach to treatment is presented per the AUA/SUFU guidelines, summarizing lifestyle modifications (firstline), pharmacotherapy (second-line), and surgical and interventional therapies (third-line), and concluding with a discussion regarding new treatment developments in advanced therapies.

\section{Pathophysiology}

Several etiologies for $\mathrm{OAB}$ have been defined: (1) myogenic detrusor overactivity (DO), (2) overactive signaling by the central nervous system (CNS) causing micturition (neurogenic), and (3) alterations within the urothelium of the lower urinary tract $[8,9]$. The myogenic hypothesis attributes DO to changes within the bladder smooth muscle that result in increased excitability and spontaneous contraction[10]. In vivo tissue studies have suggested that structural changes within the detrusor muscle in $\mathrm{OAB}$ could allow for increased conduction of electrical impulses with resultant contraction among a large proportion of muscles cells[11].

In the neurogenic hypothesis, bladder overactivity is attributed to increased neuroplasticity within the CNS[12]. Maladaptive sensory signaling from pelvic sensory nerves can instigate $\mathrm{DO}$ and precipitate $\mathrm{OAB}[13]$. Two neurotrophins, specifically brain-derived neurotrophic factor (BDNF) and nerve growth factor (NGF), have been implicated in OAB. These are modulators of neural plasticity, and individuals with OAB symptoms have demonstrated detectable amounts of these molecules in their urine[14-17]. Additionally, individuals with $\mathrm{OAB}$ exhibit varying degrees of functional connectivity in the cortex on functional MRI (fMRI) studies[18,19], and interestingly, sacral neuromodulation has been demonstrated to cause cerebral activity on fMRI[20], emphasizing the role of CNS function in OAB.

Regarding the urothelial hypothesis, research in rat models indicates that chronic urothelial injury, as modeled by intravesical injection of protamine sulfate into rats, can cause increased urinary frequency and decreased voided volumes[21]. A related hypothesis postulates that $\mathrm{OAB}$ symptoms may also be urethrogenic, that is, arising from the urethra[22]. Specifically, low urethral tone and subsequent stress urinary incontinence (SUI) or contact of urine with the proximal urethra can stimulate the proximal urethral afferent nerves that can initiate micturition via the urethrovesical reflex and, in some cases, cause symptoms of OAB. Newer areas of exploration for OAB pathophysiology include the role of sex hormones, mood disorders, and the effect of the urinary microbiome[23].

\section{OAB Treatment}

\section{Guidelines}

The AUA/SUFU OAB guidelines provide a framework clinicians can use to diagnose and stratify patients with $\mathrm{OAB}$. As acknowledged in the guidelines, there is a lack of evidence-based publications in the current literature regarding the diagnosis of $\mathrm{OAB}$. A clinical principle in the guidelines suggests that the initial evaluation for uncomplicated $\mathrm{OAB}$ requires only a thorough history and physical examination and a urinalysis to rule out conditions that may mimic $\mathrm{OAB}$, such as urinary tract infection or malignancy. Use of adjunct tests such as urine cultures or post-void residuals can be incorporated as deemed necessary. The guidelines also clarify that UDS, cystoscopy, and renal imaging are not indicated in the initial workup. Clinicians should also consider how $\mathrm{OAB}$ symptoms may manifest in select populations, such as men with benign prostatic hypertrophy (BPH) or women with genitourinary syndrome of menopause (GSM).

The guidelines stratify OAB treatment into several tiers: first-line (behavioral and non-pharmacologic), second-line (pharmacologic therapy), third-line (surgical and interventional therapies) and fourth-line (urinary diversion or bladder augmentation)[1]. This discussion focuses on the first 3 tiers. 


\section{FIGURE 1.}

Suggested clinical algorithm for management of $O A B$

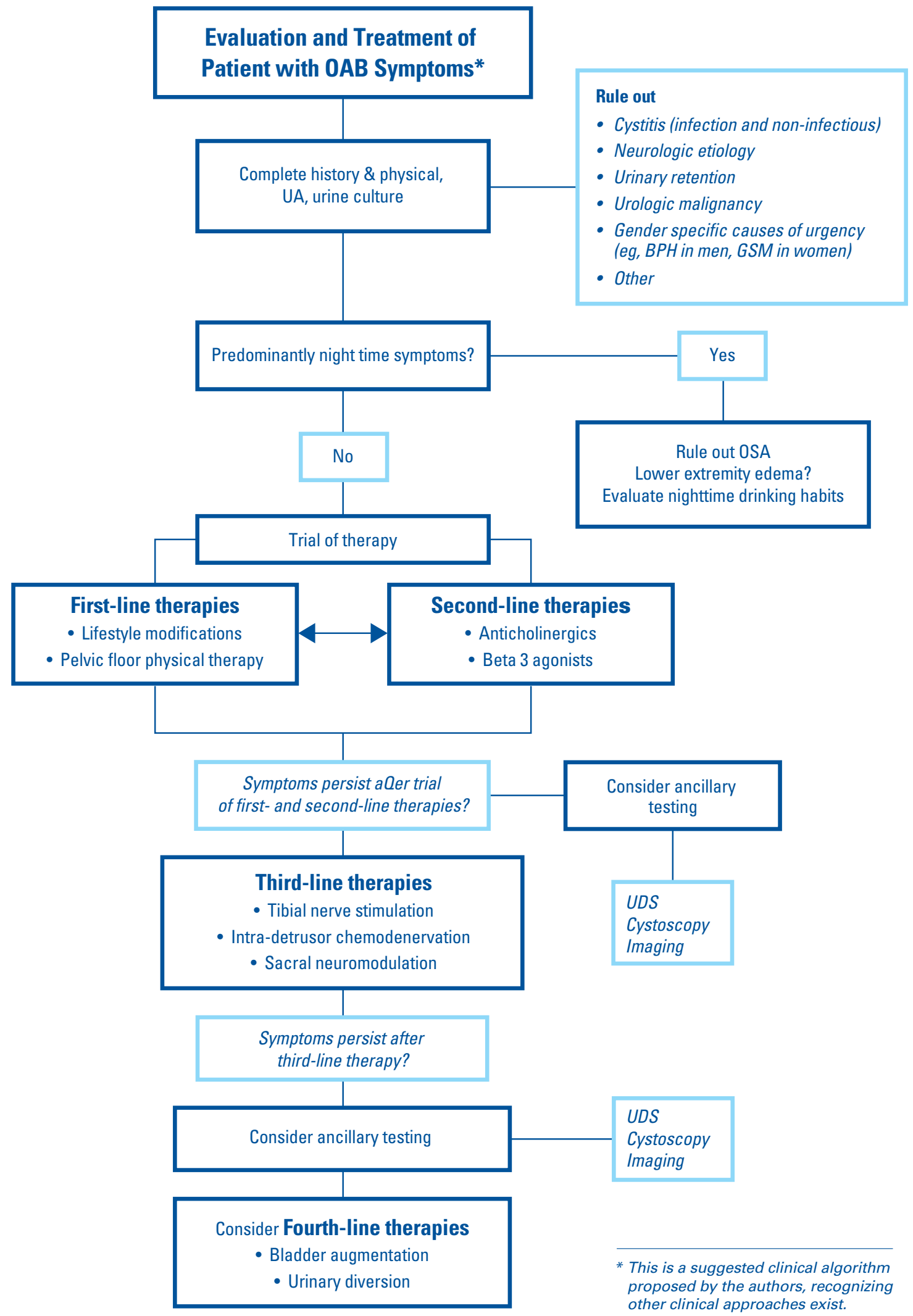




\section{First-Line Therapy}

First-line therapy for OAB includes low-risk behavioral interventions, although much of the data supporting these therapies is drawn from non-randomized controlled trials (RCT). In a study of pelvic floor biofeedback for OAB symptoms in women, 9 weeks of EMG-based biofeedback for pelvic floor muscle therapy resulted in significant symptom improvement[24]. A review exploring the role of pelvic floor muscle therapy traditionally used for SUI found the use of similar regimens in patients who had urinary urgency and OAB symptoms effectively reduced symptoms[25].

In a comprehensive review regarding urinary symptoms in overweight and obese women, weight loss showed no benefit in the reduction of urinary urgency[26]. However, in a cohort of morbidly obese patients who underwent laparoscopic sleeve gastrectomy, patients experienced a significant improvement in OAB symptoms as measured by a 3-day voiding diary and improvement on the $\mathrm{OAB}$ short form questionnaire. The mean reduction in BMI following surgery was $9 \mathrm{~kg} / \mathrm{m}^{2}$, suggesting that the magnitude of weight loss to reduce symptoms may be unattainable for many patients[27].

Smoking and dietary habits, particularly consumption of carbonated beverages, alcohol, and caffeine, can cause OAB symptoms. Accordingly, lifestyle modifications aimed at reducing smoking and dietary triggers can result in an improvement of $\mathrm{OAB}[28]$. Finally, an association between functional constipation and $\mathrm{OAB}$ has been shown[29-31], but these studies do not specifically report on the effect of treating constipation and relief of OAB.

\section{Second-Line Therapy}

\section{Anticholinergics}

Anticholinergics are a well-established pharmacotherapy for $\mathrm{OAB}[1]$. There are 5 described subtypes of muscarinic receptors, of which M2 and M3 are found in highest concentration within the bladder. While the $\mathrm{M} 2$ receptor is predominant in the bladder, the M3 receptors are most strongly associated with micturition control[32]. A review examining the effectiveness of anticholinergics versus behavioral therapy concluded that anticholinergics outperformed non-pharmacologic interventions for improvement in OAB symptoms[33].

While dry mouth and constipation are the most frequent side effects of anticholinergic medications, cognitive side effects can be profound, particularly amongst older individuals. The rates of discontinuation of anticholinergics in trial settings have been shown to be as high $80 \%[34]$. In a case- control study conducted in the United Kingdom, anticholinergic exposure was associated with dose-dependent increased odds of developing dementia[35]. This relationship has been well documented and demonstrated, particularly in older individuals[36-38]. At a molecular level, trospium's bulky quaternary amine structure limits its penetration across the blood-brain barrier, thereby reducing unwanted cognitive effects[39,40].

\section{Beta-3 agonists}

Beta-3 agonists represent a newer class of $O A B$ medication. Studies have demonstrated that mirabegron is equally efficacious as anticholinergics in their reduction of OAB symptoms[41-43]. Potential side effects include hypertension and cardiac arrythmia[44]. In a study examining the safety profile of mirabegron, there was a slight increase in hypertension with this drug compared with placebo and only among individuals over 75 (7\% versus 5\%)[45]. The absence of hypertension risk has also been reaffirmed on meta-analysis[46]. In an observational study from the UK, improvements in both quality of life and health status were seen for patients on mirabegron, with over $50 \%$ persisting on the drug at 12 months [47].

Recently approved, vibegron is a novel beta-3 agonist that has also shown efficacy in placebo-controlled studies including reduction of micturition episodes and urge incontinence episodes[48,49]. Furthermore, recent RCT data showed no difference in the rates of hypertension between patients on vibegron versus placebo[50].

Despite a higher per-pill cost of beta- 3 agonists, recent studies have demonstrated a similar cost-effectiveness between beta- 3 agonists and anticholinergics. This increased cost-effectiveness has been attributed to decreased discontinuation of beta-3 agonists, leading to improved quality of life, decreased need for third-line therapies, and decreased health care use due to adverse events[51-54].

\section{Third-Line Therapy}

Third-line therapies represent a rapidly growing category of $\mathrm{OAB}$ treatment, although they remain underutilized[55]. Existing third-line therapies include bladder chemodenervation with onabotulinumtoxin A (BTX), percutaneous tibial nerve modulation (PTNM), and sacral neuromodulation (SNM).

\section{Bladder chemodenervation with onabotulinumtoxinA}

Chemodenervation involves the prevention of presynaptic release of acetylcholine (ACh) thereby averting excitation of ACh-dependent smooth muscle within the detrusor and reducing bladder contractions[56]. Data also suggest that the toxin may decrease sensory input during bladder filling via its effect on ATP-regulated signaling mechanisms[56-58].

BTX is administered cystoscopically with injections distributed throughout the bladder[59,60]. Complete 
resolution of urinary incontinence has been shown to be higher amongst those receiving BTX (27\%) compared with those on anticholinergics (13\%)[61]. BTX also outperforms placebo for the reduction of OAB symptoms, with 2.95 fewer daily UUI episodes compared with 1 fewer observed with a placebo after 12 weeks of treatment [58]. BTX injection also appears to be of therapeutic value for all patients with idiopathic $O A B$, regardless of whether $\mathrm{DO}$ is present on pretreatment urodynamics[62]. One of the potential risks of BTX is urinary retention. However, the definition of retention is not standardized across the BTX reports, and this has contributed to the widely variable (2\% to $35 \%)$ rates reported in the literature. The risk of retention appears to be dose-dependent[63-66]. Studies have demonstrated a median of 7.6 months of symptom relief following BTX injection[67]. There are data suggesting that the production of neutralizing antibodies can result in tachyphylaxis with successive treatments with BTX. However, this risk has been drastically lowered with newer formulation of the toxin[68].

\section{Percutaneous tibial nerve modulation}

Performed in the clinic setting, PTNM involves 12 weekly in-office sessions during which a 34 -gauge needle is placed cephalad to the medial malleolus and posterior to the tibia. The posterior tibial nerve is stimulated at varying frequencies with an external generator. The hypothesized mechanism of action involves modulation of bladder contraction via both afferent and efferent pathways of the tibial nerve[69,70].

PTNM has shown success in patients with refractory OAB. In a study of patients undergoing a 12-week study course, a $25 \%$ reduction in mean daytime urinary urgency, a $35 \%$ reduction in number UUI episodes, and a $21 \%$ reduction in nighttime frequency was reported[71]. Adverse effects of PTNM are rare and include bruising, pain, and bleeding at the needle site[59]. PTNM therefore remains a well-tolerated and efficacious option for the treatment of OAB. Despite this, there remains a high drop-out rate, with retrospective data indicating an over $40 \%$ discontinuation rate[72], similar to the drop-out rates reported with BTX. Only $40 \%$ to $60 \%$ of patients receive a second injection, with subsequent treatments decreasing even further[73-75].

The updated $\mathrm{OAB}$ guidelines include a specific statement that the guidelines do not represent a stepby-step algorithm that must be followed in successive order. Consequently, a study that showed success with PTNM in drug-naïve $\mathrm{OAB}$ patients was of interest. In a single-arm study of drug-naïve $\mathrm{OAB}$ patients with $>3$ UUI episodes a day, $78 \%$ of patients saw a $50 \%$ reduction in their UUI episodes, with $40 \%$ achieving complete continence[76].

\section{Sacral neuromodulation}

Sacral neuromodulation is an operative procedure, performed in 2 stages. During the first stage, a tined lead connected to an external generator is inserted into the S3 foramina. If the patient experiences a $\geq 50 \%$ improvement in their symptoms during the 1 to 2 week trial period, a permanent impulse generator (IPG) is inserted into a subcutaneous pocket low back/upper buttock[77]. Alternatively, the first stage can be done in the office setting as a peripheral nerve evaluation with temporary bilateral leads, with or without fluoroscopic guidance. If successful, the lead and IPG can subsequently be placed in a single procedure.

SNM has been shown to be well tolerated and more efficacious than standard medical therapy. In a study comparing SNM with anticholinergic medical therapy, $76 \%$ of the SNM arm experienced therapeutic success ( $\geq 50 \%$ improvement) compared with $49 \%$ of the medical arm[78]. While the ROSETTA trial suggested a slight advantage of BTX over SNM in reducing OAB symptoms, this trial used an unconventional 200-unit dose of BTX, as opposed to the accepted 100 units for idiopathic $\mathrm{OAB}[79]$. This initial advantage of BTX was not noted at 2 years. In the 2 -year follow-up, $72 \%$ of patients randomized to BTX had required a second injection, with half of these individuals requiring a third[80].

In a retrospective analysis of state claims data, $38 \%$ of all patients who undergo SNM implantation undergo a lead revision within 5 years of their initial lead implantation, approximately two-thirds for device malfunction and the remaining third for treatment failure [81]. Another consideration with SNM is magnetic resonance imaging (MRI) compatibility. In mid-2020, a full-body MRI-compatible lead became FDA-approved and available for implantation; patients can safely undergo a full-body MRI with a 1.5 or 3 Tesla magnet for up to 30 minutes without a rest period. However, it is important to consider the implications of the leads placed before the availability of the new leads, with which patients should not undergo MRI below the neck. A review examining neuromodulation, both PTNS and $\mathrm{SNM}$, for OAB found that overall SNM was both well tolerated and effective in improving OAB symptoms. There are no long-term data describing PTNS success against SNM[82].

\section{New technologies in third-line therapy}

New chemodenervation options are being studied. Data suggest that chimeric alternatives to the BTX toxin, such as the BoNT/BMY-WW toxin have stronger affinity for nerve terminal binding, which modulates bladder effects[83]. Intravesical instillation of BTX mixed with hydrogel to promote a slower release of drug without 
the need for injection has been demonstrated to be well tolerated in interstitial cystitis patients[84]. While BTX hydrogel is still in the trial phase as part of the APOLLO study, the potential to deliver BTX "topically" via urinary catheter as opposed to via cystoscopic injections could significantly enhance the ease of delivery [85].

New technologies for PTNM are also in development. The eCoin is an implantable device, approximately the size of a nickel, that is placed along the course of the patient's posterior tibial nerve. It can be placed in the office setting and implantation minimizes the need for weekly visits. During clinical trials, $68 \%$ of subjects demonstrated at least 50\% reduction in UUI episodes at 48 weeks [86]. Another investigational technology is the StimGuard device. An internal lead is placed near the posterior tibial nerve, which can be stimulated with an external device that remains with the patient. The ongoing PROTECT trial is a multicenter RCT designed to evaluate StimGuard for non-inferiority of versus traditional SNM for OAB[87].

While traditional SNM devices require a stepwise procedure to insert the leads and subsequently a permanent IPG, the AHLeveeS System from Neuspera Medical Inc. provides an alternative approach. This new device is a miniature implantable stimulator that can be placed into the $\mathrm{S} 3$ foramen and differs from the existing SNM technology in that in lieu of an internal IPG, the AHLeveeS System uses an external wireless generator. The use of this device in a small pilot study was seen to produce physiologic responses consistent with adequate stimulation of the S3 nerve root foramina, including bellows and great toe plantarflexion[88]. Table 1 shows the major third-line therapies and the corresponding emerging technologies for $\mathrm{OAB}$.

\section{Definition of Success for Interventions}

As the presentation of $\mathrm{OAB}$ is heterogenous, defining success in the management of $\mathrm{OAB}$ can be challenging. A systematic review published in 2014 sought to assess what current research uses to define success in $\mathrm{OAB}$ trials. In this review, number of UUI episodes was the most common metric used to assess treatment efficacy, with treatment response defined as a reduction in UUI episodes of between $50 \%$ and $100 \%$ from baseline. Other symptom-based markers of treatment response were number of urgency episodes per day, voids per day, and changes in urodynamic parameters[89]. The adoption of patient-reported outcomes (PROs) has increased in biomedical and clinical research, and PRO tools are now more commonly used in OAB research $[90,91]$. The use of PROs as opposed to disease-oriented or symptom-based endpoints can provide a standardized means of communicating symptoms between patients and their physicians in the preoperative setting, thereby facilitating improved expectation and goal-setting before medical or surgical intervention for OAB [92].

\section{Special Clinical Considerations}

\section{Nocturia}

Nocturia, defined as needing to awaken at least one or more times per night to void, is one of the most common lower urinary tract symptoms (LUTS)[93]. While nocturia can be related to urologic disorders such as $\mathrm{OAB}$ or $\mathrm{BPH}$, a variety of non-urologic conditions can also cause nocturia. Among these are diabetes, heart failure, and sleep apnea $[60,93,94]$. In patients with nocturia-predominant $\mathrm{OAB}$ symptoms, urologists should investigate possible alternative diagnoses that may explain a patient's symptoms. In patients with

\section{TABLE 1.}

Third-line therapies for $O A B$ and future directions 
bothersome nocturia, 24-hour urine testing to evaluate for nocturnal polyuria should be considered, as should referral for sleep studies in patients who have a history of snoring or obstructive sleep apnea.

\section{Considerations for Neurogenic Bladder}

LUTS and OAB-like symptoms are highly prevalent in individuals with neurologic conditions, such as stroke or multiple sclerosis[95]. Up to $80 \%$ of MS patients will have bladder dysfunction in their lifetime, with $10 \%$ of all MS patients demonstrating urinary symptoms as the initial manifestation[96]. The approach to patients with neurogenic bladder can mirror the approach to those without neurologic disease, starting with first- and second-line therapies and escalating to advanced therapies [97]. Pharmacotherapy, particularly anticholinergics, have been shown efficacious in managing $\mathrm{OAB}$ amongst those with neurogenic bladder, although higher doses are often required[98]. While BTX is the only FDA-approved therapy for neurogenic bladder, it should be noted that some studies have demonstrated that neuromodulation provides benefit to neurogenic patients with refractory $\mathrm{OAB}[99]$.

\section{Sex Differences in Overactive Bladder Management}

The genitourinary syndrome of menopause (GSM), previously referred to as vulvovaginal atrophy, refers to all collective genitourinary symptoms associated with a decreasing level of estrogen in perimenopausal women[100]. Twenty percent of postmenopausal women report severe urinary urgency, and nearly $50 \%$ of these women have some form of urinary incontinence[101]. Both topical therapies, such as vaginal estrogen, and non-topical options, such as selective estrogen receptor modulators (ospemifene and lasofoxifene in particular), have been shown to improve urinary symptoms among women with GSM[99,100,102]. At the authors' institutions, women with GSM and a history of breast or gynecological malignancy are frequently treated with local estrogen following consultation with their oncologist and shared-decision making with the patient.

While $\mathrm{OAB}$ prevalence is approximately equal between men and women, women are more likely to present with UUI[103]. As alluded to in the AUA/SUFU guidelines, men presenting with OAB-like symptoms should be screened for $\mathrm{BPH}[1]$. However, OAB is still common among men with $\mathrm{BPH}$, with up to $75 \%$ of men with $\mathrm{BPH}$ having clinical symptoms of $\mathrm{OAB}$ or $\mathrm{DO}$ on UDS[104]. Therefore, clinicians should consider a concomitant diagnosis of $\mathrm{OAB}$ in men with persistent LUTS despite treatment for BPH. In general, although sex-specific factors should be considered in any approach to $\mathrm{OAB}$ evaluation, treatment should be patient-specific based on both the presenting symptoms and patient goals of care.

\section{Conclusion}

$\mathrm{OAB}$ is a complex clinical syndrome that can have a serious impact on patient quality of life. From lifestyle modifications to implantable devices, the wide spectrum of available $\mathrm{OAB}$ therapies provides clinicians a large armamentarium to help alleviate OAB symptoms for their patients. This review explores various treatment modalities for $\mathrm{OAB}$ along with recent developments, with a particular emphasis on third-line therapies. Despite their high-efficacy rates compared to first- and second-line therapies, third-line treatments for $\mathrm{OAB}$ continue to be underutilized. In recent years, however, there has been a rapid growth and development of novel therapies. These new technologies allow for more patient-centered and tailored approaches to managing $\mathrm{OAB}$ symptoms, making it an exciting time to be a clinician treating $\mathrm{OAB}$. 


\section{References}

1. Gormley E, Lightner D, Burgio K, Chai T, Clemens J, Culkin D, et al. Diagnosis and treatment of overactive bladder (non-neurogenic) in adults: AUA/SUFU guideline. J Urol.2012 Dec 2012;188(6 Suppl) doi:10.1016/j.juro.2012.09.079

2. Irwin D, Milsom I, Hunskaar S, Reilly K, Kopp Z, Herschorn S, et al. Population-based survey of urinary incontinence, overactive bladder, and other lower urinary tract symptoms in five countries: results of the EPIC study. Eur Urol.2006 Dec;50(6)doi:10.1016/j.eururo.2006.09.019

3. Stewart W, Van Rooyen J, Cundiff G, Abrams P, Herzog A, Corey R, et al. Prevalence and burden of overactive bladder in the United States. World J Urol.2003 May 2003;20(6)doi:10.1007/s00345-002-0301-4

4. Coyne K, Sexton C, Irwin D, Kopp Z, Kelleher C, Milsom I. The impact of overactive bladder, incontinence and other lower urinary tract symptoms on quality of life, work productivity, sexuality and emotional well-being in men and women: results from the EPIC study. BJU Int.2008 Jun 2008;101(11)doi:10.1111/j.1464-410X.2008.07601.x

5. Irwin D, Mungapen L, Milsom I, Kopp Z, Reeves P, Kelleher C. The economic impact of overactive bladder syndrome in six Western countries. BJU Int.2009 Jan 2009;103(2)doi:10.1111/j.1464-410X.2008.08036.x

6. Tikkinen K, Auvinen A. Does the imprecise definition of overactive bladder serve commercial rather than patient interests? Eur Urol.2012 Apr 2012;61(4)doi:10.1016/j.eururo.2011.12.013

7. Haylen B, de Ridder D, Freeman R, Swift S, Berghmans B, Lee J, et al. An International Urogynecological Association (IUGA)/International Continence Society (ICS) joint report on the terminology for female pelvic floor dysfunction. Int Urogynecol J.2010 Jan 2010;21(1) doi:10.1007/s00192-009-0976-9

8. Meng E, Lin W-Y, Lee W-C, Chuang Y-C. Pathophysiology of overactive bladder. Low Urin Tract Symptoms.2012;4(s1):48-55. doi:https://doi. org/10.1111/j.1757-5672.2011.00122.x

9. Wein A, Rackley R. Overactive bladder: a better understanding of pathophysiology, diagnosis and management. J Urol.2006 Mar 2006;175(3 Pt 2)doi:10.1016/S0022-5347(05)00313-7

10. Brading A. A myogenic basis for the overactive bladder. Urology.1997 Dec;50(6A Suppl)doi:10.1016/s0090-4295(97)00591-8

11. Haferkamp A, Dörsam J, Elbadawi A. Ultrastructural diagnosis of neuropathic detrusor overactivity: validation of a common myogenic mechanism. Adv Exp Med Biol.2003;539(Pt A) doi:10.1007/978-1-4419-8889-8_20

12. Yoshimura N. Lower urinary tract symptoms (LUTS) and bladder afferent activity. Neurourol Urodyn.2007 0ct;26(6 Suppl)doi:10.1002/ nau.20487

13. O'Reilly B, Kosaka A, Knight G, Chang T, Ford A, Rymer J, et al. P2X receptors and their role in female idiopathic detrusor instability. J Urol.2002 Jan 2002;167(1).
14. Antunes-Lopes T, Pinto R, Barros SC, Botelho F, Silva CM, Cruz CD, et al. Urinary neurotrophic factors in healthy individuals and patients with overactive bladder. J Urol.2013 Jan;189(1):359-65. doi: 10.1016/j. juro.2012.08.187. Epub 2012 Nov 19.

15. Ochodnicky P, Cruz CD, Yoshimura N, Cruz F. Neurotrophins as regulators of urinary bladder function. Nat Rev Urol.2012-10-09 2012;9(11):628-637. doi:doi:10.1038/nrurol.2012.178

16. Frias B, Lopes T, Pinto R, Cruz F, Cruz C. Neurotrophins in the lower urinary tract: becoming of age. Curr Neuropharmacol.2011 Dec 2011;9(4)doi:10.2174/157015911798376253

17. Antunes-Lopes T, Carvalho-Barros S, Cruz C-D, Cruz F, Martins-Silva C. Biomarkers in overactive bladder: a new objective and noninvasive tool? Adv Urol.2011. doi:https://doi.org/10.1155/2011/382431

18. Zuo L, Chen J, Wang S, Zhou Y, Wang B, Gu H. Intra- and inter-restingstate networks abnormalities in overactive bladder syndrome patients: an independent component analysis of resting-state fMRI. World $\mathrm{J}$ Urol.2020 Apr 2020;38(4)doi:10.1007/s00345-019-02838-z

19. Zuo L, Zhou Y, Wang S, Wang B, Gu H, Chen J. Abnormal brain functional connectivity strength in the overactive bladder syndrome: a resting-state fMRI study. Urology.2019 Sep;131doi:10.1016/j. urology.2019.05.019

20. Weissbart S, Bhavsar R, Rao H, Wein A, Detre J, Arya L, et al. Specific changes in brain activity during urgency in women with overactive bladder after successful sacral neuromodulation: a functional magnetic resonance imaging study. J Urol.2018 Aug;200(2)doi:10.1016/j. juro.2018.03.129

21. Shioyama R, Aoki Y, Ito H, Matsuta Y, Nagase K, Oyama N, et al. Long-lasting breaches in the bladder epithelium lead to storage dysfunction with increase in bladder PGE2 levels in the rat. Am J Physiol Regul Integr Comp Physiol.2008 Aug;295(2):R714-8. doi: 10.1152/ajpregu.00788.2007. Epub 2008 Jun 11.

22. Jung $S$, Fraser M, Ozawa $H$, Yokoyama O, Yoshiyama $M$, De Groat $W$, et al. Urethral afferent nerve activity affects the micturition reflex; implication for the relationship between stress incontinence and detrusor instability. J Urol.1999 Jul 1999;162(1) doi:10.1097/00005392-199907000-00069

23. Peyronnet B, Mironska E, Chapple C, Cardozo L, Oelke M, Dmochowski $\mathrm{R}$, et al. A comprehensive review of overactive bladder pathophysiology: on the way to tailored treatment. Eur Urol.2019 Jun 2019;75(6)doi:10.1016/j.eururo.2019.02.038

24. Voorham J, De Wachter S, Van den Bos T, Putter H, Lycklama À Nijeholt G, Voorham-van der Zalm P. The effect of EMG biofeedback assisted pelvic floor muscle therapy on symptoms of the overactive bladder syndrome in women: a randomized controlled trial. Neurourol Urodyn.2017 Sep 2017;36(7)doi:10.1002/nau.23180 
25. Burgio K. Update on behavioral and physical therapies for incontinence and overactive bladder: the role of pelvic floor muscle training. Curr Urol Rep.2013;14(5)doi:10.1007/s11934-013-0358-1

26. Yazdany T, Jakus-Waldman S, Jeppson P, Schimpf M, Yurteri-Kaplan L, Ferzandi T, et al. American Urogynecologic Society systematic review: the impact of weight loss intervention on lower urinary tract symptoms and urinary incontinence in overweight and obese women. Female Pelvic Med Reconstr Surg.Jan/Feb 2020;26(1)doi:10.1097/ SPV.0000000000000802

27. Palleschi G, Pastore A, Rizzello M, Cavallaro G, Silecchia G, Carbone A. Laparoscopic sleeve gastrectomy effects on overactive bladder symptoms. J Surg Res.2015;196(2)doi:10.1016/j.jss.2015.03.035

28. Dallosso H, McGrother C, Matthews R, Donaldson M. The association of diet and other lifestyle factors with overactive bladder and stress incontinence: a longitudinal study in women. BJU Int.2003 Jul 2003;92(1)doi:10.1046/j.1464-410x.2003.04271.x

29. Coyne KS, Cash B, Kopp Z, Gelhorn H, Milsom I, Berriman S, et al. The prevalence of chronic constipation and faecal incontinence among men and women with symptoms of overactive bladder. BJU Int.2011;107(2):254-61. doi: 10.1111/j.1464-410X.2010.09446.x

30. Maeda T, Tomita M, Nakazawa A, Sakai G, Funakoshi S, Komatsuda $A$, et al. female functional constipation is associated with overactive bladder symptoms and urinary incontinence. Biomed Res Int.2017. doi:https://doi.org/10.1155/2017/2138073

31. Abreu GE, Dourado ER, Alves DN, Araujo MQ, Mendonça NSP, Barroso Junior U. Functional constipation and overactive bladder in women: a population-based study. Arq Gastroenterol.2018 Nov;55Suppl 1/Suppl 1):35-40. doi: 10.1590/S0004-2803.201800000-46.

32. Andersson K. Antimuscarinics for treatment of overactive bladder. Lancet Neurol.2004 Jan;3(1)doi:10.1016/s1474-4422(03)00622-7

33. Alhasso A, McKinlay J, Patrick K, Stewart L. Anticholinergic drugs versus non-drug active therapies for overactive bladder syndrome in adults. Cochrane Database Syst Rev.2006;(4)doi:10.1002/14651858. CD003193.pub3

34. Sexton CC, Notte SM, Maroulis C, Dmochowski RR, Cardozo L, Subramanian $\mathrm{D}$, et al. Persistence and adherence in the treatment of overactive bladder syndrome with anticholinergic therapy: a systematic review of the literature. Int J Clin Pract.2011 May;65(5) doi:10.1111/j.1742-1241.2010.02626.x

35. Coupland CAC, Division of Primary Care UoN, Nottingham, England, Hill T, et al. Anticholinergic drug exposure and the risk of dementia: a nested case-control study. JAMA Intern Med.2020;179(8):1084-1093. doi:10.1001/jamainternmed.2019.0677

36. Carrière I, Fourrier-Reglat A, Dartigues J, Rouaud O, Pasquier F, Ritchie $\mathrm{K}$, et al. Drugs with anticholinergic properties, cognitive decline, and dementia in an elderly general population: the 3-city study. Arch Internal Med.2009;169(14):1317-1324. doi:10.1001/archinternmed.
37. Jessen F, Kaduszkiewicz H, Daerr M, Bickel H, Pentzek M, Riedel-Heller $S$, et al. Anticholinergic drug use and risk for dementia: target for dementia prevention. Eur Arch Ppsychiatry Clin Neurosci.2010 Nov; 260 (Suppl 2): S111-5. doi:10.1007/s00406-010-0156-4

38. Gray S, Anderson M, Dublin S, Hanlon J, Hubbar R, Walker R, et al. Cumulative use of strong anticholinergic medications and incident dementia. JAMA Intern Med.2015;175(3):401-407.

39. Staskin D. Trospium chloride: distinct among other anticholinergic agents available for the treatment of overactive bladder. Urol Clin North Am.2006 Nov;33(4)doi:10.1016/j.ucl.2006.06.006

40. Geller E, Dumond J, Bowling J, Khandelwal C, Wu J, Busby-Whitehead $\mathrm{J}$, et al. Effect of trospium chloride on cognitive function in women aged 50 and older: a randomized trial. Female Pelvic Med Reconstr Surg.Mar/Apr 2017;23(2)doi:10.1097/SPV.0000000000000374

41. Chapple C, Cardozo L, Nitti V, Siddiqui E, Michel M. Mirabegron in overactive bladder: a review of efficacy, safety, and tolerability. Neurourol Urodyn.2014 Jan;33(1)doi:10.1002/nau.22505

42. Kuo H, Lee K, Na Y, Sood R, Nakaji S, Kubota Y, et al. Results of a randomized, double-blind, parallel-group, placebo- and activecontrolled, multicenter study of mirabegron, a $\beta 3$-adrenoceptor agonist, in patients with overactive bladder in Asia. Neurourol Urodyn.2015 Sep;34(7)doi:10.1002/nau.22645

43. Wagg A, Cardozo L, Nitti V, Castro-Diaz D, Auerbach S, Blauwet M, et al. The efficacy and tolerability of the $\beta 3$-adrenoceptor agonist mirabegron for the treatment of symptoms of overactive bladder in older patients. Age Ageing.2014 Sep;43(5)doi:10.1093/ageing/afu017

44. Cui Y, Zong H, Yang C, Yan H, Zhang Y. The efficacy and safety of mirabegron in treating OAB: a systematic review and meta-analysis of phase III trials. Int Urol Nephrol.2014 Jan;46(1)doi:10.1007/ s11255-013-0509-9

45. Chapple C, Cruz F, Cardozo L, Staskin D, Herschorn S, Choudhury N, et al. Safety and efficacy of mirabegron: analysis of a large integrated clinical trial database of patients with overactive bladder receiving mirabegron, antimuscarinics, or placebo. Eur Urol.2020 Jan;77(1) doi:10.1016/j.eururo.2019.09.024

46. Chen H, Chen T, Chang H, Juan Y, Huang W, Pan H, et al. Mirabegron is alternative to antimuscarinic agents for overactive bladder without higher risk in hypertension: a systematic review and meta-analysis. World J Urol.2018 Aug;36(8)doi:10.1007/s00345-018-2268-9

47. Foley S, Choudhury N, Huang M, Stari A, Nazir J, Freeman R. Quality of life in patients aged 65 years and older with overactive bladder treated with mirabegron across eight European countries: secondary analysis of BELIEVE. Int J Urol. 2019 Sep;26(9)doi:10.1111/iju.14050 
48. Shi $H$, Chen $H$, Zhang $Y$, Cui $Y$. The efficacy and safety of vibegron in treating overactive bladder: A systematic review and pooled analysis of randomized controlled trials. Neurourol Urodyn.2020 Jun;39(5) doi:10.1002/nau.24387

49. Yoshida M, Takeda M, Gotoh M, Nagai S, Kurose T. Vibegron, a novel potent and selective $\beta 3$-adrenoreceptor agonist, for the treatment of patients with overactive bladder: a randomized, double-blind, placebocontrolled phase 3 study. Eur Urol.2018 May;73(5)doi:10.1016/j. eururo.2017.12.022

50. Staskin D, Frankel J, Varano S, Shortino D, Jankowich R, Paul N, et al. International phase iii, randomized, double-blind, placebo and active controlled study to evaluate the safety and efficacy of vibegron in patients with symptoms of overactive bladder: EMPOWUR.J Urol.2020 Aug;doi:10.1097/JU.0000000000000807

51. Nazir J, Maman K, Neine M, Briquet B, Odeyemi I, Hakimi Z, et al. Costeffectiveness of mirabegron compared with antimuscarinic agents for the treatment of adults with overactive bladder in the United Kingdom. Value Health.2015 Sep;18(6)doi:10.1016/j.jval.2015.05.011

52. Wielage R, Perk S, Campbell N, Klein T, Posta L, Yuran T, et al. Mirabegron for the treatment of overactive bladder: costeffectiveness from US commercial health-plan and Medicare Advantage perspectives. J Med Econ.2016 Dec;19(12)doi:10.1080/1 3696998.2016.1204307

53. Perk S, Wielage R, Campbell N, Klein T, Perkins A, Posta L, et al. Estimated budget impact of increased use of mirabegron, a novel treatment for overactive bladder. J Manag Care Spec Pharm.2016 Sep;22(9)doi:10.18553/jmcp.2016.22.9.1072

54. Fogaing C, Mossa A, Campeau L. Are beta 3 adrenergic agonists now the preferred pharmacologic management of overactive bladder? Curr Urol Rep.2020;21(12):49. doi:10.1007/s11934-020-01003-z

55. Moskowitz D, Adelstein S, Lucioni A, Lee U, Kobashi K. Use of third line therapy for overactive bladder in a practice with multiple subspecialty providers-are we doing enough? J Urol.2018 Mar 2018;199(3) doi:10.1016/j.juro.2017.09.102

56. Vianello A, Proietti S, Giannantoni A. Effect of botulinum neurotoxin on the urinary bladder: novel insights on mechanism of action. Minerva Urol Nefrol.2010 Sep;62(3):259-271.

57. Dolly J, Aoki K. The structure and mode of action of different botulinum toxins. Eur J Neurol.2006 Dec;13 Suppl 4doi:10.1111/j.1468-1331.2006.01648.x

58. Collins V, Daly D, Liaskos M, McKay N, Sellers D, Chapple C, et al. OnabotulinumtoxinA significantly attenuates bladder afferent nerve firing and inhibits ATP release from the urothelium. BJU Int.2013 Nov;112(7)doi:10.1111/bju.12266

59. Emami M, Shadpour P, Kashi A, Choopani M, Zeighami M. Abobotulinum - a toxin injection in patients with refractory idiopathic detrusor overactivity: injections in detrusor, trigone and bladder neck or prostatic urethra, versus detrusor - only injections. Int Braz J Urol. Nov-Dec 2017;43(6)doi:10.1590/S1677-5538.IBJU.2016.0622
60. Lowenstein L, Kenton K, Brubaker L, Pillar G, Undevia N, Mueller E, et al. The relationship between obstructive sleep apnea, nocturia, and daytime overactive bladder syndrome in women. Am J Obstet Gynecol.2008 May;198(5)doi:10.1016/j.ajog.2008.02.024

61. Visco A, Brubaker L, Richter H, Nygaard I, Paraiso MFR, Menefee SA, et al. Anticholinergic therapy vs. onabotulinumtoxina for urgency urinary incontinence. N Engl J Med.2012;367(19):1803-1813. doi:10.1056/ NEJMoa1208872

62. Rovner E, Kennelly M, Schulte-Baukloh H, Zhou J, Haag-Molkenteller C, Dasgupta P. Urodynamic results and clinical outcomes with intradetrusor injections of onabotulinumtoxinA in a randomized, placebo-controlled dose-finding study in idiopathic overactive bladder. Neurourol Urodyn.2011 Apr;30(4)doi:10.1002/nau.21021

63. Osborn DJ, Kaufman MR, Mock S, Guan MJ, Dmochowski RR, Reynolds WS. Urinary retention rates after intravesical onabotulinumtoxinA injection for idiopathic overactive bladder in clinical practice and predictors of this outcome. Neurourol Urodyn.Sep 2015;34(7):675-8. doi:10.1002/nau.22642

64. Flynn MK, Amundsen CL, Perevich M, Liu F, Webster GD. Outcome of a randomized, double-blind, placebo controlled trial of botulinum $A$ toxin for refractory overactive bladder. J Urol.Jun 2009;181(6):2608-15. doi:10.1016/j.juro.2009.01.117

65. Dmochowski R, Chapple C, Nitti V, Chancellor M, Everaert K, Thompson $C$, et al. Efficacy and safety of onabotulinumtoxinA for idiopathic overactive bladder: a double-blind, placebo controlled, randomized, dose ranging trial. J Urol.2010 Dec;184(6)doi:10.1016/j. juro.2010.08.021

66. Dowson C, Watkins J, Khan M, Dasgupta P, Sahai A. Repeated botulinum toxin type $A$ injections for refractory overactive bladder: medium-term outcomes, safety profile, and discontinuation rates. Eur Urol.2012 Apr;61(4)doi:10.1016/j.eururo.2011.12.011

67. Nitti V, Ginsberg D, Sievert K, Sussman D, Radomski S, Sand P, et al. Durable efficacy and safety of long-term onabotulinumtoxina treatment in patients with overactive bladder syndrome: final results of a 3.5-year study. J Urol.2016 Sep;196(3)doi:10.1016/j.juro.2016.03.146

68. Patel A, Patterson J, Chapple C. Botulinum toxin injections for neurogenic and idiopathic detrusor overactivity: a critical analysis of results. Eur Urol.2006 0ct;50(4)doi:10.1016/j.eururo.2006.07.022

69. Statskin D, Peter K, MacDiarmid S, Shore N, deGroat WC. Percutaneous tibial nerve stimulation: a clinically and cost effective addition to the overactive bladder algorithm of care. Curr Urol Rep.2012;13(5):327-334.

70. Gaziev G, Topazio L, lacovelli V, Asimakopoulos A, Di Sant A, De Nunzio $C$, et al. Percutaneous tibial nerve stimulation (PTNS) efficacy in the treatment of lower urinary tract dysfunctions: a systematic review. BMC Urol.2013;13(61)

71. Govier F, Litwiller S, Nitti V, Kreder K, Rosenblatt P. Percutaneous afferent neuromodulation for the refractory overactive bladder: results of a multicenter study. J Urol.2001 Apr;165(4):1193-1198. DOI: https:// doi.org/10.1016/S0022-5347(05)66469-5 
72. Te Dorsthorst $M$, Heesakkers J, van Balken M. Long-term real-life adherence of percutaneous tibial nerve stimulation in over 400 patients. Neurourol Urodyn.2020 Feb;39(2)doi:10.1002/nau.24254

73. Eldred-Evans D, Sahai A. Medium- to long-term outcomes of botulinum toxin A for idiopathic overactive bladder. Therapeutic Adv Urol.2017 Jan;9(1)doi:10.1177/1756287216672180

74. Lee W, Du C, Donahue R, Lucioni A, Kobashi K, Lee U. Majority of onabotulinumtoxina-naive patients with idiopathic overactive bladder do not repeat chemodenervation: factors affecting patient dropout after initial treatment with 100 units. J Urol.2020;203(4S).

75. Tam J, Nguyen A, Du C, Wang Q, Hung M, Weissbart S, et al. Patients have poor compliance with repeat onabotulinumtoxin a injections for overactive bladder. Presented at: AUA 2018, May 19; San Francisco. J Urol.2018;199(4S, Suppl):e646-e647. Available at: https://www. auajournals.org/doi/pdf/10.1016/j.juro.2018.02.1549. Accessed July $31,2021$.

76. Kobashi K, Nitti V, Margolis E, Sand P, Siegel S, Khandwala S, et al. A prospective study to evaluate efficacy using the nuro percutaneous tibial neuromodulation system in drug-naïve patients with overactive bladder syndrome. Urology.2019 Sep 2019;131doi:10.1016/j. urology.2019.06.002

77. Hubsher C, Jansen R, Riggs D, Jackson B, Zaslau S. Sacral nerve stimulation for neuromodulation of the lower urinary tract. Canadian J Urol.2012;19(5):6480-6484.

78. Siegel S, Noblett K, Mangel J, Griebling T, Sutherland S, Bird E, et al. Results of a prospective, randomized, multicenter study evaluating sacral neuromodulation with InterStim therapy compared to standard medical therapy at 6-months in subjects with mild symptoms of overactive bladder. Neurourol Urodyn.2015 Mar;34(3)doi:10.1002/ nau. 22544

79. Amundsen C, Richter H, Menefee S, Komesu Y, Arya L, Gregory W, et al. OnabotulinumtoxinA vs sacral neuromodulation on refractory urgency urinary incontinence in women: a randomized clinical trial. JAMA.2016;316(13)doi:10.1001/jama.2016.14617

80. Amundsen C, Komesu Y, Chermansky C, Gregory W, Myers D, Honeycutt $E$, et al. Two-year outcomes of sacral neuromodulation versus onabotulinumtoxina for refractory urgency urinary incontinence: a randomized trial. Eur Urol.2018 Jul;74(1)doi:10.1016/j. eururo.2018.02.011

81. Chughtai B, Thomas D, Sun T, Sedrakyan A. Failures of sacral neuromodulation for incontinence. JAMA Surg.2018;153(5)doi:10.1001/ jamasurg.2017.6093

82. Tutolo M, Ammirati E, Heesakkers J, Kessler T, Peters K, Rashid T, et al. Efficacy and safety of sacral and percutaneous tibial neuromodulation in non-neurogenic lower urinary tract dysfunction and chronic pelvic pain: a systematic review of the literature. Eur Urol.2018 Mar;73(3) doi:10.1016/j.eururo.2017.11.002
83. Thaker H, Zhang S, Diamond D, Dong M. Beyond botulinum neurotoxin A for chemodenervation of the bladder. Curr Opin Urol.2021;1;31(2):140146. DOI:10.1097/MOU.0000000000000843

84. Rappaport Y, Zisman A, Jeshurun-Gutshtat M, Gerassi T, Hakim G, Vinshtok $Y$, et al. Safety and feasibility of intravesical instillation of botulinum toxin-a in hydrogel-based slow-release delivery system in patients with interstitial cystitis-bladder pain syndrome: a pilot study. Urology.2018 Apr;114doi:10.1016/j.urology.2017.12.028

85. ClinicalTrials.gov. APOLLO: the study of an investigational drug, patisiran (ALN-TTR02), for the treatment of transthyretin (TTR)mediated amyloidosis. Full text view. 2021. Available at: https:// clinicaltrials.gov/ct2/show/NCT01960348. Accessed July 31, 2021.

86. Rogers A, Bragg S, Ferrante K, Thenuwara C, Peterson D. Pivotal study of leadless tibial nerve stimulation with eCoin $®$ for urgency urinary incontinence: an open-label, single arm trial. J Urol.2021 Aug;206(2):399-408. doi: 10.1097/JU.0000000000001733.

87. ClinicalTrials.gov. CAN-Stim compared to SNS in treatment of urinary urgency incontinence with wireless neuromodulation technology - full text view - clinicaltrials.gov. Available at: https://clinicaltrials.gov/ct2/ show/NCT02577302. Accessed July 30, 2021.

88. van Kerrebroeck P, Reekmans M, van Koeveringe G, Yeh A, Fayram T, Sharan A, et al. First-in-human implantation of a mid-field powered neurostimulator at the sacral nerve: results from an acute study. Neurourol Urodyn.2019 Aug;38(6)doi:10.1002/nau.24035

89. Goldman H, Wyndaele J, Kaplan S, Wang J, Ntanios F. Defining response and non-response to treatment in patients with overactive bladder: a systematic review. Curr Med Res Opin.2014 Mar;30(3)doi: 10.1185/03007995.2013.860021

90. Deshpande PR, Rajan S, Sudeepthi BL, Abdul Nazir CP. Patient-reported outcomes: a new era in clinical research. Perspect Clin Res.2011 Oct;2(4):137-44. doi: 10.4103/2229-3485.86879. PMID: 22145124; PMCID: PMC3227331

91. Speight J, Barendse S. FDA guidance on patient reported outcomes. BMJ.2010;340:c2921. doi: 10.1136/bmj.c2921.

92. Marschall-Kehrel D, Roberts R, Brubaker L. Patient-reported outcomes in overactive bladder: the influence of perception of condition and expectation for treatment benefit. Urology.2006 Aug;68(2 Suppl) doi:10.1016/j.urology.2006.02.046

93. Weiss JP. Nocturia: focus on etiology and consequences. Rev Urol.2012;14(3-4):48-55.

94. Arslan B, Gezmis C, Çetin B, Gönültas S, Gökmen E, Gürkan D, et al. Is obstructive sleep apnea syndrome related to nocturia? Low Urin Tract Symptoms.2019 May;11(3)doi:10.1111/luts.12250 
95. Wein A, Dmochowski R. Neuromuscular dysfunction of the lower urinary tract. In: Partin A, Peters C, Kavoussi L, Dmchowski R, Wein A, eds. Campbell Walsh Wein Urology. Elsevier; 2020.

96. Aharony S, Lam 0, Corcos J. Evaluation of lower urinary tract symptoms in multiple sclerosis patients: Review of the literature and current guidelines. Can Urol Assoc J.2017;11:61-64.

97. Kurpad R, Kennelly M. The evaluation and management of refractory neurogenic overactive bladder. Curr Urol Rep.2014 0ct;15(10) doi:10.1007/s11934-014-0444-z

98. Kennelly M, Devoe W. Overactive bladder: pharmacologic treatments in the neurogenic population. Rev in urology.2008;10(3).

99. Sanford M, Suskind A. Neuromodulation in neurogenic bladder. Transl Androl Urol.2016 Feb;5(1)doi:10.3978/j.issn.2223-4683.2015.12.01

100. Portamn D, LS Gass M, Panel VATCC. Genitourinary syndrome of menopause: new terminology for vulvovaginal atrophy from the International Society for the Study of Women's Sexual Health and the North American Menopause Society. J Sex Med.2014 Dec;11(12) doi:10.1111/jsm.12686
101. Kim H, Kang S, Chung Y, Kim J, Kim M. The recent review of the genitourinary syndrome of menopause. J Menopausal Med.2015;21(2):65-71. doi:10.6118/jmm.2015.21.2.65

102. Schiavi M, Sciuga V, Giannini A, Vena F, D'oria O, Prata G, et al. Overactive bladder syndrome treatment with ospemifene in menopausal patients with vulvovaginal atrophy: improvement of sexuality? Gynecol Endocrinol.2018 Aug;34(8)doi:10.1080/0951359 0.2018 .1441398

103. Eapen R, Radomski S. Gender differences in overactive bladder. Can J Urol.2016 Feb 2016;23(Suppl 1):2-9.

104. Dmochowski R. Overactive bladder in males. Therapeutic Adv Urol.2009;1(4):209-221. 